\title{
Passing the torch: Let us make sure it remains lit
}

\author{
Francisco Igor Macedo, MD, a,b and Tomas A. Salerno, $\mathrm{MD}^{\mathrm{a}}$
}

\author{
From the ${ }^{\mathrm{a} D i v i s i o n}$ of Cardiothoracic Surgery, and ${ }^{\mathrm{b}}$ Dewitt-Daughtry Department of Surgery, Jackson Memorial \\ Hospital and the University of Miami Miller School of Medicine, Miami, Fla. \\ Disclosures: Authors have nothing to disclose with regard to commercial support. \\ Received for publication June 3, 2018; revisions received June 3, 2018; accepted for publication June 4, 2018; \\ available ahead of print July 26, 2018 \\ Address for reprints: Tomas A. Salerno, MD, Jackson Memorial Hospital and the University of Miami Miller \\ School of Medicine, 1611 NW 12th Ave, Miami, FL 33136 (E-mail: tsalerno@med.miami.edu). \\ J Thorac Cardiovasc Surg 2018;156:2233-4 \\ $0022-5223 / \$ 36.00$ \\ Copyright (C) 2018 by The American Association for Thoracic Surgery \\ https://doi.org/10.1016/j.jtcvs.2018.06.011
}

Technological advances in cardiology and cardiac surgery, with the expanded use of modern percutaneous interventions, mechanical assist devices, minimally invasive and robotic surgery, and the use of hybrid and stenting procedures, led surgeons to have to leave the operating room and work in collaboration with cardiologists. ${ }^{1}$ Brazilian cardiac surgeons have faced this reality and have modified their educational programs to meet the requirements for board certification eligibility, achieved via a comprehensive training and examination processes.

In this issue of the Journal, Rocha and Almeida ${ }^{2}$ present the model of cardiac surgery training in Brazil, highlighting recent changes in its curricula to adjust to current challenges. Considering the number of surgeon innovators and pioneers that have come from Brazilian programs, one concludes that their trainees are getting an excellent education and preparation for a surgical career. Recently, the Brazilian programs have implemented an integrated program in cardiac surgery, with elimination of previous general surgery training requirements. In the United States, the number of applicants to traditional cardiothoracic fellowship training has steadily declined, whereas applicants to integrated programs have increased. ${ }^{3}$ In our opinion, this has undoubtedly provided a more focused and effective training. However, this model is still questioned by older generation of surgeons who feel that the trainee is better prepared if he/she receives full general surgery training before entrance into a cardiothoracic program.

A major challenge in the training of future surgeons is the limited volume of appropriate teaching cases. Simulationbased learning has appeared as an option to offset this issue, providing an opportunity to master various surgical component skill sets during off-duty periods, thereby enhancing the value of formal residency experience. Several simulation models have been integrated into US programs, and a formal curriculum has been successfully implemented by a collaborative work involving multiple institutions. ${ }^{4}$ It seems that Brazilian training programs also enhanced their simulation models, because part of the board certification in and pioneers.

\section{References}

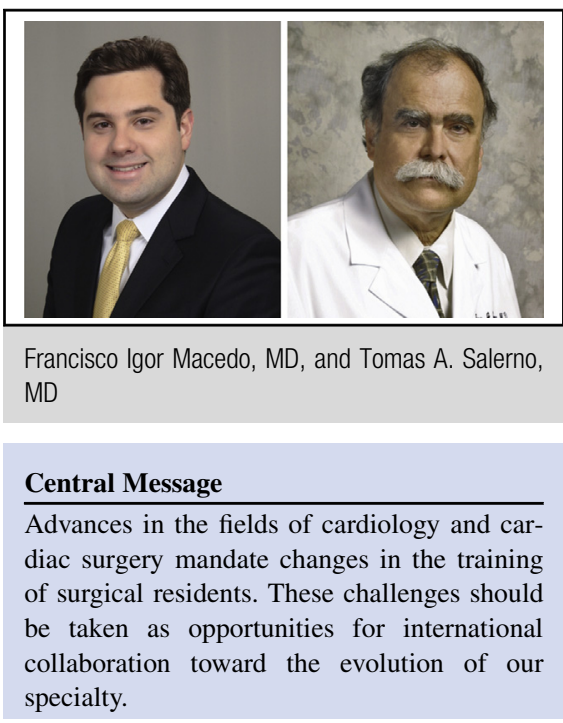

See Article page 2227.

Brazil includes the demonstration of proficiency in performing cardiac operations. This emphasizes the importance of technical ability and knowledge, putting demands on the mentors who train the resident.

The trainees' limited exposure in the operating room is aggravated by the implementation of work-hour restrictions. Interestingly, the work hours for the cardiac trainees in Brazil are limited to 60 hours a week, ${ }^{2}$ far less than the 80-hour per week workload in the United States. It would be worthwhile to assess whether this difference has any impact on case volume, patient care, academic productivity, and pass rates at board certification examinations.

Knowledge passes from generation to generation of surgeons, beginning with our trainees. The future of our specialty lies in their hands, a fact that sometimes is overlooked. From the experience with Brazilian training programs, it is time to further implement international collaboration, as we have a lot to learn from other international programs. The training program in Brazil exemplifies how surgeons, facing challenges, molded their programs to meet the expectations to train the future generation of cardiac surgeons, following in the tradition of their role models

1. Salerno TA. In my opinion: a realistic view of the cardiothoracic surgery specialty CTSnet 2002. Available at: https://www.ctsnet.org/article/realistic-viewcardiothoracic-surgery-specialty. Accessed June 1, 2018.

2. Rocha RV, Almeida RM. Cardiac surgery residency in Brazil: how to deal with the challenges of this unique specialty. J Thorac Cardiovasc Surg. 2018;156:2227-32. 
3. Vaporciyan AA, Reed CE, Erikson C, Dill MJ, Carpenter AJ, Guleserian KJ, et al Factors affecting interest in cardiothoracic surgery: survey of North American general surgery residents. J Thorac Cardiovasc Surg. 2009;137:1054-62.
4. Feins RH, Burkhart HM, Conte JV, Coore DN, Fann JI, Hicks GL Jr, et al. Simulation-based training in cardiac surgery. Ann Thorac Surg. 2017;103: $312-21$ 